OPEN ACCESS

Edited by:

Suhasini Joshi,

Memorial Sloan Kettering Cancer

Center, United States

Reviewed by:

Valeria De Pasquale,

University of Naples Federico II, Italy

Francesca Di Sole,

Des Moines University, United States

Garima Kaushik,

Champions Oncology, Inc.,

United States

${ }^{*}$ Correspondence:

Mara Brancaccio

mara.brancaccio@

unito.it

Specialty section:

This article was submitted to

Cellular Biochemistry,

a section of the journal

Frontiers in Cell and Developmental

Biology

Received: 02 July 2021

Accepted: 20 September 2021

Published: 14 October 2021

Citation:

Poggio P, Sorge $M$, Secli L and Brancaccio M (2021) Extracellular HSP90 Machineries Build Tumor Microenvironment and Boost Cancer

Progression.

Front. Cell Dev. Biol. 9:735529.

doi: 10.3389/fcell.2021.735529

\section{Extracellular HSP90 Machineries Build Tumor Microenvironment and Boost Cancer Progression}

\author{
Pietro Poggio, Matteo Sorge, Laura Secli and Mara Brancaccio* \\ Department of Molecular Biotechnology and Health Sciences, University of Torino, Torino, Italy
}

HSP9O is released by cancer cells in the tumor microenvironment where it associates with different co-chaperones generating complexes with specific functions, ranging from folding and activation of extracellular clients to the stimulation of cell surface receptors. Emerging data indicate that these functions are essential for tumor growth and progression. The understanding of the exact composition of extracellular HSP9O complexes and the molecular mechanisms at the basis of their functions in the tumor microenvironment may represent the first step to design innovative diagnostic tools and new effective therapies. Here we review the impact of extracellular HSP9O complexes on cancer cell signaling and behavior. Keywords: eHSP90 (Extracellular Heat Shock Protein 90), tumor microenvironment, CDC37, Clusterin, CHORDC1,
Morgana, LRP1, TLR (toll like receptors)

\section{INTRODUCTION}

In order to survive and proliferate in a highly stressful environment cancer cells upregulate chaperone expression and actively release chaperones in the extracellular milieu to guarantee their survival and sustain their aberrant evolution toward malignancy (Velichko et al., 2013).

The Heat Shock Protein 90 (HSP90) is a highly conserved and ubiquitously expressed chaperone essential for cell survival. It represents the $1-2 \%$ of the total protein content and plays multiple roles, ranging from protein folding to buffering protein denaturation and assisting protein conformational changes (Schopf et al., 2017). Overexpression of HSP90 promotes cell survival, sustains oncogenic signal transduction, cell proliferation and migration (Jaeger and Whitesell, 2019). High HSP90 levels are frequent in human cancer and correlates with poor prognosis (Cheng et al., 2012), with the exception of some specific tumor contexts (Nanbu et al., 1998).

HSP90 comes in two isoforms, the stress-induced HSP90 $\alpha$ and the constitutively expressed HSP90 $\beta$ (Sreedhar et al., 2004). In physiological conditions, normal cells express more HSP90 $\beta$ than HSP90 $\alpha$ (Ullrich et al., 1989) while in cancer cells HSP90 $\alpha$ doubles HSP90ß expression level (Zuehlke et al., 2015; Dong et al., 2016). HSP90 $\alpha$ underexpression correlates with favorable outcome in some cancer types (Gallegos Ruiz et al., 2008; Buffart et al., 2012). 


\section{THE INTRACELLULAR HSP90 MACHINERY}

HSP90 forms a flexible homodimer and binds to its clients, promoting modifications in their structure in an ATP dependent manner. A single monomer of HSP90 is composed by three domains: an N-terminal ATP-binding domain, a middle domain and a C-terminal dimerization domain. In order to fold client proteins, the HSP90 dimer undergoes conformational rearrangements switching between a closed $\mathrm{N}$-terminal conformation and an open one (Figure 1A). Co-chaperones bind sequentially and reversibly to HSP90 to regulate its conformational changes, its ATPase activity and to confer specificity to clients. Client proteins are bound by the HSP70/HSP40 complex, which is stabilized by HSP70interacting protein (HIP). The HSP90/HSP70 organizing protein (HOP) facilitates the interaction between HSP90 and HSP70 and the translocation of the client protein to HSP90 (Schopf et al., 2017). The HSP70/HOP complex stabilizes HSP90 in the open conformation and inhibits its ATPase activity. This state primes the binding of peptidyl-prolyl isomerases (PPIases), such as FK506 Binding Proteins (FKBP51 and FKBP52), which support cycle progression. Activator of HSP90 ATPase homolog 1 (AHA1) weakens the interaction between HOP and HSP90, promoting HOP and HSP70 release and the transition toward the N-terminal closed state (closed 1). The binding of p23 displaces AHA1, inducing the switch to a completely closed state (closed 2), which is followed by ATP hydrolysis, the return to the open conformation and the release of the client together with p23 and PPIases (Rohl et al., 2013). Cell division cycle 37 homolog (CDC37) is a crucial HSP90 ATPase-inhibiting co-chaperone which stabilizes the HSP90 open form and recruits kinase clients (Siligardi et al., 2002; Taipale et al., 2012). The protein phosphatase and co-chaperone PP5 associates with HSP90 N-terminal domain and dephosphorylates HSP90 and CDC37, regulating client protein processing ( $\mathrm{Li}$ et al., 2012). The ability to interact with HSP90 N-terminal domain is also a property of CHORD (Cysteine and Histidine Rich Domain) containing proteins. Indeed, Morgana and Melusin bind to HSP90 preferentially when it is in an ADP-bound state (Gano and Simon, 2010), favoring the protection of cells from different stress stimuli (Michowski et al., 2010; Ferretti et al., 2011; Sorge and Brancaccio, 2016).

\section{EXTRACELLULAR HSP90}

HSP90 emerged as one of the more abundant secreted chaperones in normal cells as keratinocytes, dermal fibroblasts and neurons (Sidera et al., 2004; Sidera and Patsavoudi, 2008; Li et al., 2012, 2013; Bhatia et al., 2016). The lack of a secretory signal peptide and experimental data (Santos et al., 2017; Kim et al., 2018) indicate that chaperone secretion relies on unconventional mechanisms. HSP90 secretion can be induced by various environmental stimuli. Hypoxia-inducible factor 1 alpha (HIF1 $\alpha$ ) stabilization in hypoxic conditions (Li et al., 2007; Sahu et al., 2012) and extracellular signal-regulated kinase (ERK) pathway activation in response to oxidative stress (Liao et al., 2000) are both able to stimulate HSP90 secretion. In the extracellular compartment, HSP90 may exist in a soluble form, but it can be also found bound to phospholipids on plasma membrane and even on the surface or inside exosomes (Shevtsov et al., 2020). eHSP90 $\alpha$ promotes cell migration and invasion, crucial processes in tissue morphogenesis, embryonic development, and wound healing processes (Wong and Jay, 2016).

\section{eHSP90 IN CANCER PROGRESSION}

The release of HSP90, mainly HSP90 $\alpha$, from cancer cells and its role in promoting cancer cell survival, migration, invasion, and stemness through autocrine mechanisms is well established (Liu et al., 2019; Secli et al., 2021). Cells of the tumor microenvironment also express HSP90 receptors and several studies reported the binding of HSP90 to their surface (Calderwood et al., 2016). eHSP90 $\alpha$ may mediate fibroblast migration and conversion to cancer associated fibroblasts (Bohonowych et al., 2014; Tang et al., 2019) as well as migration and tubulogenesis in lymphatic endothelial cells (Hou et al., 2021). By interacting with immune cells in the tumor microenvironment, HSP90 may also exert anti-tumoral functions. Indeed, HSP90 is released from cancer cells bound to oncopeptides and facilitates their presentation to antigen presenting cells, stimulating anti-cancer immunity and tumor regression (Calderwood et al., 2016). Nevertheless, the amount of HSP90 $\alpha$ in patient serum correlates with tumor progression and the presence of distant metastasis (Liu et al., 2019, 2021).

eHSP90 pro-tumoral activity occurs with different mechanisms. It can activate extracellular clients, promoting the formation of a favorable milieu for cell migration or it can bind to surface receptors stimulating cell survival, movement and aggressiveness (Li et al., 2013).

eHSP90 clients include several proteins involved in extracellular matrix remodeling, like metalloproteinases (MMP2 and MMP9) (Song et al., 2010; Stellas et al., 2010; Sims et al., 2011; Baker-Williams et al., 2019), the pro-form of tissue plasminogen activator (tPA) (McCready et al., 2010), the lysil oxidase-like protein 2 (LOXL2), and fibronectin (Boel et al., 2018; Chakraborty et al., 2020). This suggests that eHSP90 has the potential to regulate matrix deposition and stiffness, thus influencing cancer aggressiveness (De Maio and Vazquez, 2013; Kai et al., 2016; Wong and Jay, 2016).

eHSP90 binds to several cell surface receptors and triggers signal transduction pathways that contribute to malignancy. It interacts with Toll-like receptor 4 (TLR4) and signals via Proto-oncogene tyrosine-protein kinase (SRC) to focal adhesion kinase (FAK), which is critical for cell motility. eHSP90-mediated TLR4 activation may also induce the transactivation of the epithelial growth factor receptor (EGFR), further contributing to malignancy (Thuringer et al., 2011). Binding to the extracellular domain of HER2, eHSP90 unleashes SRC, ERK, and RAC-alpha serine/threonine-protein kinase (AKT) pathways (BelschesJablonski et al., 2001; Sidera et al., 2008). eHSP90 also interacts with low-density lipoprotein receptor-related protein 1 (LRP1). 


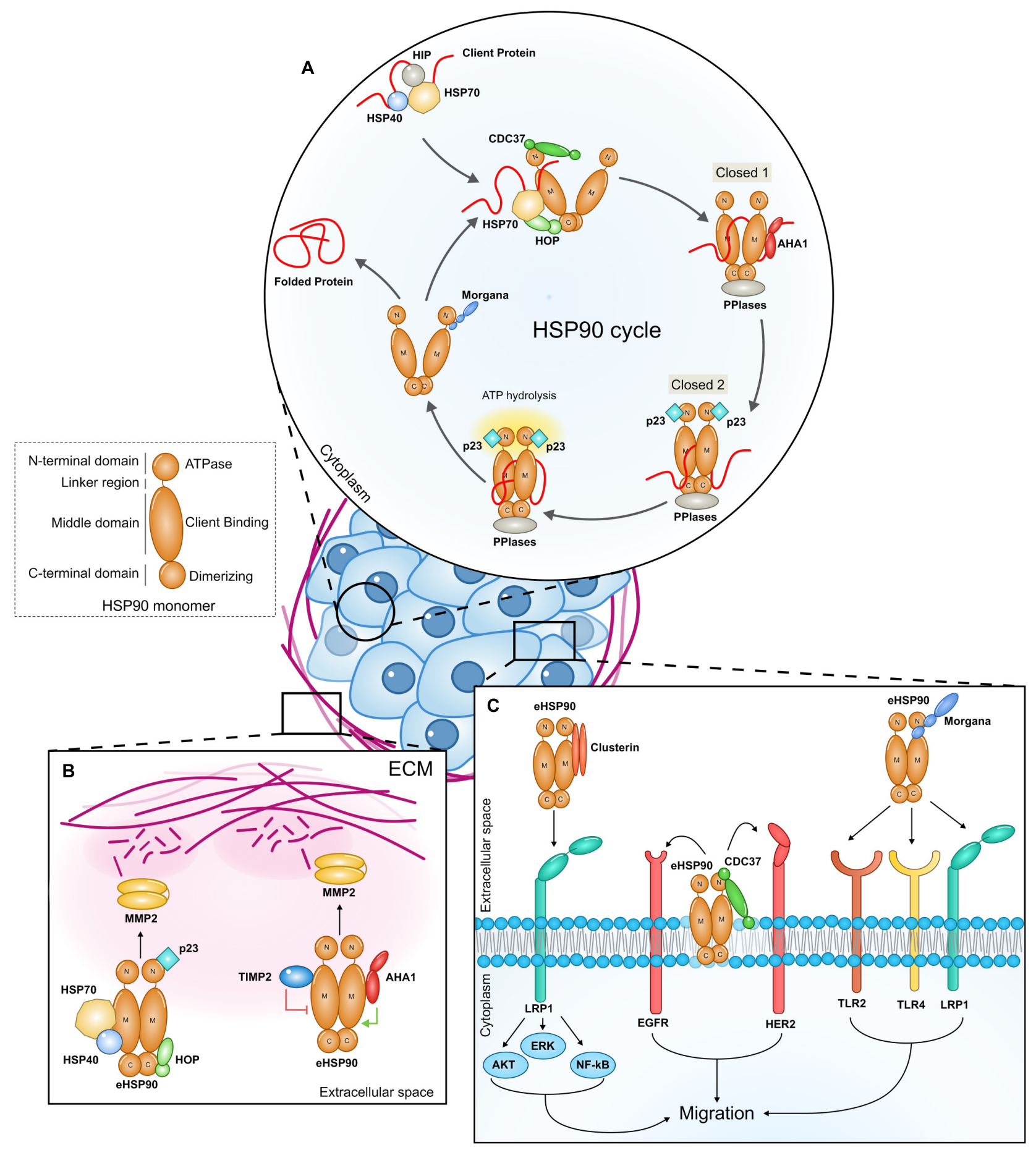

FIGURE 1 | (A) The intracellular HSP90 cycle. The figure highlights the role of co-chaperones that participate to the HSP90 intracellular machinery and that have been also found to be part of extracellular HSP90 complexes. The client protein is initially bound by the HSP70/HSP40 complex and then stabilized by HSP70-interacting protein (HIP). The client protein is loaded onto HSP90 from the HSP70/HSP40 protein complex thanks to the adaptor protein HOP (HSP90-HSP70 organizing protein). The co-chaperone CDC37 (cell-division-cycle 37 homolog) is required by HSP90 to bind client kinases. As the client protein is loaded, other co-chaperones, peptidyl-prolyl-isomerase and PPlases (FKBP51, FKBP52) join the complex while the HSP70, HIP, and HOP are released. AHA1 (activator of HSP90 ATPase homolog 1) binding induces HSP90 to switch from the open state to the closed 1 state, while p23 induces ATP hydrolysis and the transition toward the closed 2 conformation. The co-chaperone Morgana interacts with HSP90 in the ADP-bound state. (B,C) Extracellular HSP90 (eHSP90) complexes promote cancer cell migration. eHSP90 released by cancer cells binds to different secreted co-chaperones in the extracellular milieu. eHSP90 complexes interact with extracellular client proteins favoring ECM remodeling (B) and with surface receptors (C), triggering intracellular signal transduction (ECM, extracellular matrix; M, HSP9o Middle domain; C, HSP90 C terminal domain; N, HSP90 N terminal domain). 
LRP1 is a ubiquitous endocytic receptor that recognizes several ligands and transduces signals, regulating tissue remodeling, cell survival and inflammatory reactions (Calderwood, 2018). eHSP90 binding to LRP1 activates ERK, AKT, and NF- $\mathrm{B}$ pathways and induces ephrin type-A receptor 2 (EPHA2) recruitment and activation, promoting lamellipodia formation and cancer cell motility and invasion (Chen et al., 2010; Gopal et al., 2011; Tsen et al., 2013; Nagaraju et al., 2015).

Interestingly, a small eHSP90 $\alpha$-specific fragment, located at the boundary between the linker and the $\mathrm{M}$ domain, is sufficient to reproduce the ability of the entire chaperone to induce cell migration trough LRP1 (Cheng et al., 2011; Zou et al., 2017). Nevertheless, increasing evidence indicates that eHSP90 protumorigenic activity is regulated and directed by secreted cochaperones (Table 1). This suggests that co-chaperones may regulate the accessibility of the HSP90 pro-motility fragment, besides conferring specificity to clients and receptors.

\section{eHSP9O COMPLEXES REMODEL TUMOR MICROENVIRONMENT}

Four co-chaperones, namely HSP70, HSP40, HOP, and p23 were found in complex with eHSP90 $\alpha$ in breast cancer cell conditioned medium. These factors increase eHSP90 $\alpha$ binding to MMP2, enhancing MMP2 activation and resulting in cancer cell invasion (Figure 1B). HSP70 depletion from conditioned media or its pharmacological inhibition impairs eHSP90-mediated MMP2 activation (Sims et al., 2011). Similar multichaperone complexes have been found also in other contexts. eHSP90 $\alpha$ and eHSP70 released on the surface of extracellular vesicles are responsible for tumor-induced muscle wasting. Both HSP70 and HSP90 $\alpha$ are required to activate TLR4 on muscle cells to induce cachexia (Zhang et al., 2017), however it is not clear if a direct interaction occurs. Experiments in neuroblasts demonstrate that eHOP, eHSP70, and eHSP90 cooperate to influence cell migration, suggesting the possibility that these chaperones generate a functional complex (Miyakoshi et al., 2017). In these studies, the presence of further components has not been investigated.

In fibrosarcoma cell conditioned medium, eHSP90 $\alpha$ requires an articulated competing system between co-chaperones to induce client maturation (Baker-Williams et al., 2019). Researchers identified the Tissue inhibitor of metalloproteinase 2 (TIMP2), an endogenous inhibitor of MMPs, as a new extracellular co-chaperone of eHSP90 $\alpha$. TIMP2 forms a complex with eHSP90 $\alpha$, PP5 and HOP and inhibits eHSP90 $\alpha$ ATPase activity by binding its middle domain. In this context, TIMP2 functions as a scaffolding co-chaperone that loads MMP2 to eHSP90 $\alpha$, keeping MMP2 in a transiently inhibited state. AHA1 competes with TIMP2 for the binding to the HSP90 $\alpha$-MMP2 complex (Figure 1B). Indeed, TIMP2, and AHA1 occupy the same epitope on the M-domain of eHSP90 $\alpha$ and AHA1 may displace TIMP2 from the HSP90 $\alpha$-MMP2 complex, promoting the full activation of the metalloproteinase and inducing matrix degradation. The evidence for sequential events influencing eHSP90 complex composition and client activation suggests the existence of bona fide eHSP90 machineries. It remains a matter of debate if HSP90 extracellular functions are dependent on its ATPase activity. Many studies have proposed and demonstrated that eHSP90 can chaperone clients in an ATP independent manner (Cheng et al., 2011; Sims et al., 2011; McCready et al., 2014), however Baker-Williams et al. (2019) proved that eHSP90 needs ATP hydrolysis to properly fold MMP2. Since cells can actively secrete ATP in response to a variety of stressful stimuli (Di Virgilio, 2021), it is possible that, at least in some contexts, eHSP90 binds, and hydrolases ATP to carry out its extracellular duties.

\section{eHSP90 COMPLEXES ACTIVATE CANCER CELL SURFACE RECEPTORS}

Several co-chaperones assist and regulate eHSP90 binding to cell surface receptors, likely conferring binding specificity and/or promoting specific signaling events.

CDC37 has been found secreted by triple negative breast cancer cells and localized on the cell surface (El Hamidieh et al., 2012). Similarly to its intracellular counterpart, eCDC37 acts as a co-factor of eHSP90. The HSP90 isoform involved in this specific complex has not been investigated. The eHSP90/eCDC37 complex interacts on the cell surface with HER2 and EGF receptors allowing breast cancer cell migration (Figure 1C). Indeed, treatment with anti-CDC37 antibodies impairs cancer cell migration and in vivo administration of an HSP90 blocking antibody, able to disrupt the HSP90-CDC37 complex, inhibits metastasis formation (Stellas et al., 2007, 2010; El Hamidieh et al., 2012).

Clusterin is a secreted glycoprotein that functions as an ATP-independent extracellular chaperone for several clients in extracellular fluids, acting by inhibiting amorphous protein aggregation and contributing to the clearance of unfolded proteins (Jenne and Tschopp, 1989; Calero et al., 1999; Wyatt et al., 2011). LDL Receptor Related Protein 2 (LRP2) and Plexin A4 have been identified as Clusterin receptors in brain (Kang et al., 2014, 2016). It has been demonstrated that Clusterin interacts with eHSP90 $\alpha$ and increases its ability to associate with LRP1. The Clusterin/HSP90 $\alpha$ complex binds to LRP1 with higher affinity in respect to eHP90 $\alpha$ alone and potentiates the signal, increasing breast cancer cell migration (Figure 1C). Clusterin and eHSP90 $\alpha$ synergistic signaling induces E-cadherin downregulation and increases the expression of $\mathrm{N}$-cadherin, Snail, Slug, and Zeb1, promoting epithelial to mesenchymal transition. In vivo co-administration of eHSP90 $\alpha$ and Clusterin in mice carrying breast cancer cells derived tumors significantly increases metastasis (Tian et al., 2019).

Morgana is a HSP90 co-chaperone coded by the CHORDC1 gene. Inside the cells, Morgana regulates signal transduction by binding and inhibiting Rho kinases I and II (Ferretti et al., 2010; Fusella et al., 2014) and promotes NF-kB activation (Fusella et al., 2017). It is also involved in microtubule polymerization (Palumbo et al., 2020), EGF receptor trafficking (Haag et al., 2020), and extracellular vesicle secretion (Urabe et al., 2020). We recently found that Morgana is secreted by several cancer cells through an unconventional pathway and it associates with HSP90 
TABLE 1 | Roles of extracellular HSP90 co-chaperones.

\begin{tabular}{|c|c|c|c|}
\hline Co-chaperone & Intracellular functions & $\begin{array}{l}\text { Role of eHSP90 complexes in cancer } \\
\text { progression }\end{array}$ & References \\
\hline CDC37 & $\begin{array}{l}\text { Stabilization of HSP90 open conformation; } \\
\text { presentation of kinases clients to HSP90 }\end{array}$ & $\begin{array}{l}\text { Induction of cancer cell migration through } \\
\text { HER2 and EGF receptors }\end{array}$ & $\begin{array}{l}\text { El Hamidieh et al., 2012; } \\
\text { Baker-Williams et al., } 2019\end{array}$ \\
\hline AHA1 & Induction of HSP90 ATPase activity & $\begin{array}{l}\text { Competition with TIMP2 for the activation of } \\
\text { the HSP90-MMP2 complex }\end{array}$ & Baker-Williams et al., 2019 \\
\hline p23 & Stabilization of HSP90 closed 2 state & MMP2 activation & Sims et al., 2011 \\
\hline HOP & $\begin{array}{l}\text { Stabilization of HSP90 open conformation; transfer } \\
\text { of client proteins from HSP70 to HSP90 }\end{array}$ & MMP2 activation & $\begin{array}{l}\text { Sims et al., 2011; Hajj et al., 2013; } \\
\text { Baker-Williams et al., } 2019\end{array}$ \\
\hline HIP & Transfer of client proteins from HSP70 to HSP90 & Not investigated & Crescitelli et al., 2020 \\
\hline HSP40 & $\begin{array}{l}\text { Stimulation of the association between HSP70 and } \\
\text { HIP; transfer of client proteins from HSP70 to } \\
\text { HSP90 }\end{array}$ & MMP2 activation & $\begin{array}{l}\text { Gehrmann et al., 2005; } \\
\text { Sims et al., } 2011\end{array}$ \\
\hline HSP70 & $\begin{array}{l}\text { ATP-dependent molecular chaperone; binding and } \\
\text { transfer of client proteins to HSP90 }\end{array}$ & $\begin{array}{l}\text { MMP2 activation; TLR4 } \\
\text { Activation }\end{array}$ & $\begin{array}{l}\text { Lee et al., 2006; Sims et al., 2011; } \\
\text { Guzhova et al., 2013; De Maio, } 2014\end{array}$ \\
\hline PP5 & HSP90 phosphatase & Not investigated & Baker-Williams et al., 2019 \\
\hline FKBP51/FKBP52 & $\begin{array}{l}\text { Peptidyl-prolyl-isomerase involved in client protein } \\
\text { maturation }\end{array}$ & Not investigated & Criado-Marrero et al., 2018 \\
\hline Morgana & $\begin{array}{l}\text { Form a complex with ADP-bound HSP90; } \\
\text { regulation of intracellular signaling pathways }\end{array}$ & $\begin{array}{l}\text { Induction of cancer cell migration through } \\
\text { TLR4, TLR2, and LRP1 receptors }\end{array}$ & Seclì et al., 2021 \\
\hline Clusterin & Mediation of intracellular proteostasis & $\begin{array}{l}\text { Induction of cancer cell migration through } \\
\text { LRP1 receptor }\end{array}$ & Tian et al., 2019 \\
\hline
\end{tabular}

in the extracellular milieu. The involvement of a specific HSP90 isoform has not been yet clarified. Cancer cells downregulated for Morgana migrate less than control cells and the addition of a recombinant Morgana in the medium totally rescues the defect in cell migration. HSP90 blocking antibodies revert this ability, suggesting that the eMorgana works in concert with HSP90 to promote cell migration. We found that TLR4, TLR2, and LRP1 are all required for eMorgana function (Figure 1C). Indeed, the impairment of the activity of these receptors by blocking antibodies or RNA interference makes the cells insensitive to Morgana pro-migratory signals. The available data indicate that Morgana binds directly to TLR2, while it requires additional components, present in the cancer cell conditioned medium, to bind to LRP1. The interaction between Morgana and TLR4 remains elusive and the possibility that TLR4 may participate to Morgana signal transduction thank to a cross-talk with TLR2 and LRP1 has to be taken into account. The fact that cancer cell migration in presence of Morgana blocking antibodies is not further repressed by inhibiting HSP90 suggests that the extracellular complex containing HSP90 and Morgana is the main responsible for migration, at least in a subgroup of cancer cells (Seclì et al., 2021).

\section{eHSP9O COMPLEXES AS THERAPEUTIC TARGETS}

Eighteen HSP90 inhibitors have entered clinical trials but none has been approved by the FDA, mainly due to associated toxicity (Xiao and Liu, 2020). Several pre-clinical trials are now exploring the possibility to selectively inhibit the extracellular HSP90 (Tsutsumi et al., 2008; Wang et al., 2009; Song et al., 2010). However, since eHSP90 may also induce anticancer immunity (Calderwood et al., 2016), the opportunity to specifically target eHSP90 pro-tumorigenic complexes would further improve the therapeutic value of these approaches. This strategy is achievable by targeting co-chaperones present in pro-tumorigenic complexes (Barrott and Haystead, 2013; Edkins et al., 2018; D'Annessa et al., 2020). In vitro and in vivo experiments have proved that targeting extracellular co-chaperones have the potential to inhibit cancer progression. Treatments with antibodies against AHA1 or TIMP2 are able to inhibit MMP2 activity (Baker-Williams et al., 2019). The use of cell impermeable anti-CDC37 antibody compromises the invasiveness of breast cancer tumor cells (El Hamidieh et al., 2012). Similar effects have been described in vitro and in cancer preclinical models for the monoclonal antibody against eHSP90 (4C5), able to disrupt the eCDC37/eHSP90/HER2 or EGFR complex (Stellas et al., 2007, 2010; El Hamidieh et al., 2012). A monoclonal antibody against Morgana (mAb 5B11B3) has been recently identified as an inhibitor of cancer cell migration both in vitro and in pre-clinical models. mAb 5B11B3 systemic treatment in immunocompromised tumor-bearing mice inhibits cancer cell intravasation and metastasis. In syngeneic cancer mouse models, in addition to reducing metastases, $\mathrm{mAb} 5 \mathrm{~B} 11 \mathrm{~B} 3$ abates tumor growth by promoting anti-cancer immunity mediated by macrophages and $\mathrm{CD} 8^{+} \mathrm{T}$ lymphocytes (Seclì et al., 2021).

\section{DISCUSSION}

While the role of eHSP90 as a promoter of cancer progression is well established, the involvement of its extracellular cochaperones remains poorly investigated. Available data suggest that eHSP90 binds to extracellular co-chaperones, forms different complexes and generates machineries with specific missions in the outside. Little is known on the dynamic of eHSP90 complex 
formation and on their possible cooperation in activating cell surface receptors and extracellular clients. It has been demonstrated that inside cancer cells, HSP90 can form stable aberrant multi-chaperone complexes that facilitate cell survival (Rodina et al., 2016). In the extracellular medium, similar complexes could work as platforms, clustering surface receptors and regulating their transactivation, or acting as scaffolds for extracellular matrix remodeling. A deep understanding of the eHSP90 interaction network appears a promising starting point to develop new diagnostics tools and provide potential targets for drug intervention in cancer.

\section{REFERENCES}

Baker-Williams, A. J., Hashmi, F., Budzynski, M. A., Woodford, M. R., Gleicher, S., Himanen, S. V., et al. (2019). Co-chaperones TIMP2 and AHA1 competitively regulate extracellular HSP90: client MMP2 activity and matrix proteolysis. Cell Rep. 28, 1894-1906.e96. doi: 10.1016/j.celrep.2019.07.045

Barrott, J. J., and Haystead, T. A. (2013). Hsp90, an unlikely ally in the war on cancer. FEBS J. 280, 1381-1396. doi: 10.1111/febs.12147

Belsches-Jablonski, A. P., Biscardi, J. S., Peavy, D. R., Tice, D. A., Romney, D. A., and Parsons, S. J. (2001). Src family kinases and HER2 interactions in human breast cancer cell growth and survival. Oncogene 20, 1465-1475. doi: 10.1038/ sj.onc. 1204205

Bhatia, A., O’Brien, K., Chen, M., Woodley, D. T., and Li, W. (2016). Keratinocytesecreted heat shock protein-90alpha: leading wound reepithelialization and closure. Adv. Wound Care 5, 176-184. doi: 10.1089/wound.2014.0620

Boel, N. M., Hunter, M. C., and Edkins, A. L. (2018). LRP1 is required for novobiocin-mediated fibronectin turnover. Sci. Rep. 8:11438. doi: 10.1038/ s41598-018-29531-2

Bohonowych, J. E., Hance, M. W., Nolan, K. D., Defee, M., Parsons, C. H., and Isaacs, J. S. (2014). Extracellular Hsp90 mediates an NF-kappaB dependent inflammatory stromal program: implications for the prostate tumor microenvironment. Prostate 74, 395-407. doi: 10.1002/pros.22761

Buffart, T. E., Carvalho, B., van Grieken, N. C., van Wieringen, W. N., Tijssen, M., Kranenbarg, E. M., et al. (2012). Losses of chromosome 5q and 14q are associated with favorable clinical outcome of patients with gastric cancer. Oncologist 17, 653-662. doi: 10.1634/theoncologist.2010-0379

Calderwood, S. K. (2018). Heat shock proteins and cancer: intracellular chaperones or extracellular signalling ligands? Philos. Trans. R. Soc. Lond. B Biol. Sci. 373:20160524. doi: 10.1098/rstb.2016.0524

Calderwood, S. K., Gong, J., and Murshid, A. (2016). Extracellular HSPs: the complicated roles of extracellular HSPs in immunity. Front. Immunol. 7:159. doi: $10.3389 /$ fimmu. 2016.00159

Calero, M., Tokuda, T., Rostagno, A., Kumar, A., Zlokovic, B., Frangione, B., et al. (1999). Functional and structural properties of lipid-associated apolipoprotein J (clusterin). Biochem. J. 344(Pt 2), 375-383.

Chakraborty, A., Boel, N. M., and Edkins, A. L. (2020). HSP90 interacts with the fibronectin N-terminal domains and increases matrix formation. Cells 9:272. doi: 10.3390/cells 9020272

Chen, J. S., Hsu, Y. M., Chen, C. C., Chen, L. L., Lee, C. C., and Huang, T. S. (2010). Secreted heat shock protein 90alpha induces colorectal cancer cell invasion through CD91/LRP-1 and NF-kappaB-mediated integrin alphaV expression. J. Biol. Chem. 285, 25458-25466. doi: 10.1074/jbc.M110.139345

Cheng, C. F., Sahu, D., Tsen, F., Zhao, Z., Fan, J., Kim, R., et al. (2011). A fragment of secreted HSP90alpha carries properties that enable it to accelerate effectively both acute and diabetic wound healing in mice. J. Clin. Invest. 121, 4348-4361. doi: 10.1172/JCI46475

Cheng, Q., Chang, J. T., Geradts, J., Neckers, L. M., Haystead, T., Spector, N. L., et al. (2012). Amplification and high-level expression of heat shock protein 90 marks aggressive phenotypes of human epidermal growth factor receptor 2 negative breast cancer. Breast Cancer Res. 14:R62. doi: 10.1186/bcr3168

Crescitelli, R., Lasser, C., Jang, S. C., Cvjetkovic, A., Malmhall, C., Karimi, N., et al. (2020). Subpopulations of extracellular vesicles from human metastatic

\section{AUTHOR CONTRIBUTIONS}

All authors wrote the manuscript and approved the contents for publication.

\section{FUNDING}

This work was supported by the Italian Association for Cancer Research (AIRC IG24930) and by the Regione Piemonte (Digital Technology for Lung Cancer Treatment-DEFLeCT) to MB.

melanoma tissue identified by quantitative proteomics after optimized isolation. J. Extracell. Vesicles 9:1722433. doi: 10.1080/20013078.2020.1722433

Criado-Marrero, M., Rein, T., Binder, E. B., Porter, J. T., Koren, J. III, and Blair, L. J. (2018). Hsp90 and FKBP51: complex regulators of psychiatric diseases. Philos. Trans. R. Soc. Lond. B Biol. Sci. 373:20160532. doi: 10.1098/rstb.2016.0532

D’Annessa, I., Hurwitz, N., Pirota, V., Beretta, G. L., Tinelli, S., Woodford, M., et al. (2020). Design of disruptors of the Hsp90-Cdc37 interface. Molecules 25:360. doi: 10.3390/molecules25020360

De Maio, A. (2014). Extracellular Hsp70: export and function. Curr. Protein Pept. Sci. 15, 225-231. doi: 10.2174/1389203715666140331113057

De Maio, A., and Vazquez, D. (2013). Extracellular heat shock proteins: a new location, a new function. Shock 40, 239-246. doi: 10.1097/SHK. 0b013e3182a185ab

Di Virgilio, F. (2021). P2X7 is a cytotoxic receptor.maybe not: implications for cancer. Purinergic Signal. 17, 55-61. doi: 10.1007/s11302-020-09735-w

Dong, H., Zou, M., Bhatia, A., Jayaprakash, P., Hofman, F., Ying, Q., et al. (2016). Breast cancer MDA-MB-231 cells use secreted heat shock protein-90alpha (HSP90alpha) to survive a hostile hypoxic environment. Sci. Rep. 6:20605. doi: 10.1038/srep20605

Edkins, A. L., Price, J. T., Pockley, A. G., and Blatch, G. L. (2018). Heat shock proteins as modulators and therapeutic targets of chronic disease: an integrated perspective. Philos. Trans. R. Soc. Lond. B Biol. Sci. 373:20160521. doi: 10.1098/ rstb.2016.0521

El Hamidieh, A., Grammatikakis, N., and Patsavoudi, E. (2012). Cell surface Cdc37 participates in extracellular HSP90 mediated cancer cell invasion. PLoS One 7:e42722. doi: 10.1371/journal.pone.0042722

Ferretti, R., Palumbo, V., Di Savino, A., Velasco, S., Sbroggio, M., Sportoletti, P., et al. (2010). Morgana/chp-1, a ROCK inhibitor involved in centrosome duplication and tumorigenesis. Dev. Cell 18, 486-495. doi: 10.1016/j.devcel. 2009.12.020

Ferretti, R., Sbroggio, M., Di Savino, A., Fusella, F., Bertero, A., Michowski, W., et al. (2011). Morgana and melusin: two fairies chaperoning signal transduction. Cell Cycle 10, 3678-3683. doi: 10.4161/cc.10.21.18202

Fusella, F., Ferretti, R., Recupero, D., Rocca, S., Di Savino, A., Tornillo, G., et al. (2014). Morgana acts as a proto-oncogene through inhibition of a ROCK-PTEN pathway. J. Pathol. 234, 152-163. doi: 10.1002/path.4341

Fusella, F., Secli, L., Busso, E., Krepelova, A., Moiso, E., Rocca, S., et al. (2017). The IKK/NF-kappaB signaling pathway requires Morgana to drive breast cancer metastasis. Nat. Commun. 8:1636. doi: 10.1038/s41467-017-01829-1

Gallegos Ruiz, M. I., Floor, K., Roepman, P., Rodriguez, J. A., Meijer, G. A., Mooi, W. J., et al. (2008). Integration of gene dosage and gene expression in nonsmall cell lung cancer, identification of HSP90 as potential target. PLoS One 3:e0001722. doi: 10.1371/journal.pone.0001722

Gano, J. J., and Simon, J. A. (2010). A proteomic investigation of liganddependent HSP90 complexes reveals CHORDC1 as a novel ADP-dependent HSP90-interacting protein. Mol. Cell. Proteomics 9, 255-270. doi: 10.1074/mcp. M900261-MCP200

Gehrmann, M., Marienhagen, J., Eichholtz-Wirth, H., Fritz, E., Ellwart, J., Jaattela, M., et al. (2005). Dual function of membrane-bound heat shock protein 70 (Hsp70), Bag-4, and Hsp40: protection against radiation-induced effects and target structure for natural killer cells. Cell Death Differ. 12, 38-51. doi: 10.1038/ sj.cdd. 4401510 
Gopal, U., Bohonowych, J. E., Lema-Tome, C., Liu, A., Garrett-Mayer, E., Wang, B., et al. (2011). A novel extracellular Hsp90 mediated co-receptor function for LRP1 regulates EphA2 dependent glioblastoma cell invasion. PLoS One 6:e17649. doi: 10.1371/journal.pone.0017649

Guzhova, I. V., Shevtsov, M. A., Abkin, S. V., Pankratova, K. M., and Margulis, B. A. (2013). Intracellular and extracellular Hsp70 chaperone as a target for cancer therapy. Int. J. Hyperthermia 29, 399-408. doi: 10.3109/02656736.2013.807439

Haag, A., Walser, M., Henggeler, A., and Hajnal, A. (2020). The CHORD protein CHP-1 regulates EGF receptor trafficking and signaling in C. elegans and in human cells. Elife 9:e50986. doi: 10.7554/eLife.50986

Hajj, G. N., Arantes, C. P., Dias, M. V., Roffe, M., Costa-Silva, B., Lopes, M. H., et al. (2013). The unconventional secretion of stress-inducible protein 1 by a heterogeneous population of extracellular vesicles. Cell. Mol. Life Sci. 70, 3211-3227. doi: 10.1007/s00018-013-1328-y

Hou, Q., Chen, S., An, Q., Li, B., Fu, Y., and Luo, Y. (2021). Extracellular HSP90alpha promotes tumor lymphangiogenesis and lymph node metastasis in breast cancer. Int. J. Mol. Sci. 22:7747. doi: 10.3390/ijms22147747

Jaeger, A. M., and Whitesell, L. (2019). HSP90: enabler of cancer adaptation. Ann. Rev. Cancer Biol. 3, 275-297. doi: 10.1146/annurev-cancerbio-030518-055533

Jenne, D. E., and Tschopp, J. (1989). Molecular structure and functional characterization of a human complement cytolysis inhibitor found in blood and seminal plasma: identity to sulfated glycoprotein 2, a constituent of rat testis fluid. Proc. Natl. Acad. Sci. U.S.A. 86, 7123-7127. doi: 10.1073/pnas.86.18.7123

Kai, F., Laklai, H., and Weaver, V. M. (2016). Force matters: biomechanical regulation of cell invasion and migration in disease. Trends Cell Biol. 26, 486-497. doi: 10.1016/j.tcb.2016.03.007

Kang, B. H., Shim, Y. J., Tae, Y. K., Song, J. A., Choi, B. K., Park, I. S., et al. (2014). Clusterin stimulates the chemotactic migration of macrophages through a pertussis toxin sensitive G-protein-coupled receptor and Gbetagammadependent pathways. Biochem. Biophys. Res. Commun. 445, 645-650. doi: 10. 1016/j.bbrc.2014.02.071

Kang, S. S., Kurti, A., Wojtas, A., Baker, K. E., Liu, C. C., Kanekiyo, T., et al. (2016). Identification of plexin A4 as a novel clusterin receptor links two Alzheimer's disease risk genes. Hum. Mol. Genet. 25, 3467-3475. doi: 10.1093/hmg/ddw188

Kim, J., Gee, H. Y., and Lee, M. G. (2018). Unconventional protein secretion new insights into the pathogenesis and therapeutic targets of human diseases. J. Cell Sci. 131:jcs213686. doi: 10.1242/jcs.213686

Lee, K. J., Kim, Y. M., Kim, D. Y., Jeoung, D., Han, K., Lee, S. T., et al. (2006). Release of heat shock protein 70 (Hsp70) and the effects of extracellular Hsp70 on matric metalloproteinase-9 expression in human monocytic U937 cells. Exp. Mol. Med. 38, 364-374. doi: 10.1038/emm.2006.43

Li, J., Soroka, J., and Buchner, J. (2012). The Hsp90 chaperone machinery: conformational dynamics and regulation by co-chaperones. Biochim. Biophys. Acta 1823, 624-635. doi: 10.1016/j.bbamcr.2011.09.003

Li, W., Li, Y., Guan, S., Fan, J., Cheng, C. F., Bright, A. M., et al. (2007). Extracellular heat shock protein-90alpha: linking hypoxia to skin cell motility and wound healing. EMBO J. 26, 1221-1233. doi: 10.1038/sj.emboj.7601579

Li, W., Tsen, F., Sahu, D., Bhatia, A., Chen, M., Multhoff, G., et al. (2013). Extracellular Hsp90 (eHsp90) as the actual target in clinical trials: intentionally or unintentionally. Int. Rev. Cell Mol. Biol. 303, 203-235. doi: 10.1016/B978-012-407697-6.00005-2

Liao, D. F., Jin, Z. G., Baas, A. S., Daum, G., Gygi, S. P., Aebersold, R., et al. (2000). Purification and identification of secreted oxidative stress-induced factors from vascular smooth muscle cells. J. Biol. Chem. 275, 189-196. doi: 10.1074/jbc. 275. 1.189

Liu, H., Zhang, Z., Huang, Y., Wei, W., Ning, S., Li, J., et al. (2021). Plasma HSP90AA1 predicts the risk of breast cancer onset and distant metastasis. Front. Cell Dev. Biol. 9:639596. doi: 10.3389/fcell.2021.639596

Liu, W., Li, J., Zhang, P., Hou, Q., Feng, S., Liu, L., et al. (2019). A novel pan-cancer biomarker plasma heat shock protein 90alpha and its diagnosis determinants in clinic. Cancer Sci. 110, 2941-2959. doi: 10.1111/cas.14143

McCready, J., Sims, J. D., Chan, D., and Jay, D. G. (2010). Secretion of extracellular HSP90alpha via exosomes increases cancer cell motility: a role for plasminogen activation. BMC Cancer 10:294. doi: 10.1186/1471-2407-10-294

McCready, J., Wong, D. S., Burlison, J. A., Ying, W., and Jay, D. G. (2014). An impermeant ganetespib analog inhibits extracellular Hsp90-mediated cancer cell migration that involves Lysyl oxidase 2-like protein. Cancers 6, 1031-1046. doi: $10.3390 /$ cancers 6021031
Michowski, W., Ferretti, R., Wisniewska, M. B., Ambrozkiewicz, M., Beresewicz, M., Fusella, F., et al. (2010). Morgana/CHP-1 is a novel chaperone able to protect cells from stress. Biochim. Biophys. Acta 1803, 1043-1049. doi: 10.1016/ j.bbamcr.2010.05.005

Miyakoshi, L. M., Marques-Coelho, D., De Souza, L. E. R., Lima, F. R. S., Martins, V. R., Zanata, S. M., et al. (2017). Evidence of a cell surface role for Hsp90 complex proteins mediating neuroblast migration in the subventricular zone. Front. Cell. Neurosci. 11:138. doi: 10.3389/fncel.2017.00138

Nagaraju, G. P., Long, T. E., Park, W., Landry, J. C., Taliaferro-Smith, L., Farris, A. B., et al. (2015). Heat shock protein 90 promotes epithelial to mesenchymal transition, invasion, and migration in colorectal cancer. Mol. Carcinog. 54, 1147-1158. doi: 10.1002/mc.22185

Nanbu, K., Konishi, I., Mandai, M., Kuroda, H., Hamid, A. A., Komatsu, T., et al. (1998). Prognostic significance of heat shock proteins HSP70 and HSP90 in endometrial carcinomas. Cancer Detect. Prev. 22, 549-555. doi: 10.1046/j.15251500.1998.00069.x

Palumbo, V., Tariq, A., Borgal, L., Metz, J., Brancaccio, M., Gatti, M., et al. (2020). Drosophila morgana is an Hsp90-interacting protein with a direct role in microtubule polymerisation. J. Cell Sci. 133:jcs236786. doi: 10.1242/jcs.236786

Rodina, A., Wang, T., Yan, P., Gomes, E. D., Dunphy, M. P., Pillarsetty, N., et al. (2016). The epichaperome is an integrated chaperome network that facilitates tumour survival. Nature 538, 397-401. doi: 10.1038/nature19807

Rohl, A., Rohrberg, J., and Buchner, J. (2013). The chaperone Hsp90: changing partners for demanding clients. Trends Biochem. Sci. 38, 253-262. doi: 10.1016/ j.tibs.2013.02.003

Sahu, D., Zhao, Z., Tsen, F., Cheng, C. F., Park, R., Situ, A. J., et al. (2012). A potentially common peptide target in secreted heat shock protein-90alpha for hypoxia-inducible factor-1alpha-positive tumors. Mol. Biol. Cell 23, 602-613. doi: 10.1091/mbc.E11-06-0575

Santos, T. G., Martins, V. R., and Hajj, G. N. M. (2017). Unconventional secretion of heat shock proteins in cancer. Int. J. Mol. Sci. 18:946. doi: 10.3390/ ijms 18050946

Schopf, F. H., Biebl, M. M., and Buchner, J. (2017). The HSP90 chaperone machinery. Nat. Rev. Mol. Cell Biol. 18, 345-360. doi: 10.1038/nrm.2017.20

Seclì, L., Avalle, L., Poggio, P., Fragale, G., Cannata, C., Conti, L., et al. (2021). Targeting the extracellular HSP90 co-chaperone Morgana inhibits cancer cell migration and promotes anti-cancer immunity. Cancer Res. 81, 4794-4807. doi: 10.1158/0008-5472.can-20-3150

Secli, L., Fusella, F., Avalle, L., and Brancaccio, M. (2021). The dark-side of the outside: how extracellular heat shock proteins promote cancer. Cell. Mol. Life Sci. 78, 4069-4083. doi: 10.1007/s00018-021-03764-3

Shevtsov, M., Balogi, Z., Khachatryan, W., Gao, H., Vigh, L., and Multhoff, G. (2020). Membrane-associated heat shock proteins in oncology: from basic research to new theranostic targets. Cells 9:1263. doi: 10.3390/cells 9051263

Sidera, K., and Patsavoudi, E. (2008). Extracellular HSP90: conquering the cell surface. Cell Cycle 7, 1564-1568. doi: 10.4161/cc.7.11.6054

Sidera, K., Gaitanou, M., Stellas, D., Matsas, R., and Patsavoudi, E. (2008). A critical role for HSP90 in cancer cell invasion involves interaction with the extracellular domain of HER-2. J. Biol. Chem. 283, 2031-2041. doi: 10.1074/jbc.M701803200

Sidera, K., Samiotaki, M., Yfanti, E., Panayotou, G., and Patsavoudi, E. (2004). Involvement of cell surface HSP90 in cell migration reveals a novel role in the developing nervous system. J. Biol. Chem. 279, 45379-45388. doi: 10.1074/jbc. M405486200

Siligardi, G., Panaretou, B., Meyer, P., Singh, S., Woolfson, D. N., Piper, P. W., et al. (2002). Regulation of Hsp90 ATPase activity by the cochaperone Cdc37p/p50cdc37. J. Biol. Chem. 277, 20151-20159. doi: 10.1074/ jbc.M201287200

Sims, J. D., McCready, J., and Jay, D. G. (2011). Extracellular heat shock protein (Hsp)70 and HSP90alpha assist in matrix metalloproteinase-2 activation and breast cancer cell migration and invasion. PLoS One 6:e18848. doi: 10.1371/ journal.pone.0018848

Song, X., Wang, X., Zhuo, W., Shi, H., Feng, D., Sun, Y., et al. (2010). The regulatory mechanism of extracellular Hsp90\{alpha\} on matrix metalloproteinase-2 processing and tumor angiogenesis. J. Biol. Chem. 285, 40039-40049. doi: 10. 1074/jbc.M110.181941

Sorge, M., and Brancaccio, M. (2016). Melusin promotes a protective signal transduction cascade in stressed hearts. Front. Mol. Biosci. 3:53. doi: 10.3389/ fmolb.2016.00053 
Sreedhar, A. S., Kalmar, E., Csermely, P., and Shen, Y. F. (2004). Hsp90 isoforms: functions, expression and clinical importance. FEBS Lett. 562, 11-15. doi: 10. 1016/s0014-5793(04)00229-7

Stellas, D., El Hamidieh, A., and Patsavoudi, E. (2010). Monoclonal antibody 4C5 prevents activation of MMP2 and MMP9 by disrupting their interaction with extracellular HSP90 and inhibits formation of metastatic breast cancer cell deposits. BMC Cell Biol. 11:51. doi: 10.1186/1471-2121-11-51

Stellas, D., Karameris, A., and Patsavoudi, E. (2007). Monoclonal antibody 4C5 immunostains human melanomas and inhibits melanoma cell invasion and metastasis. Clin. Cancer Res. 13, 1831-1838. doi: 10.1158/1078-0432.CCR-061585

Taipale, M., Krykbaeva, I., Koeva, M., Kayatekin, C., Westover, K. D., Karras, G. I., et al. (2012). Quantitative analysis of HSP90-client interactions reveals principles of substrate recognition. Cell 150, 987-1001. doi: 10.1016/j.cell.2012. 06.047

Tang, X., Chang, C., Guo, J., Lincoln, V., Liang, C., Chen, M., et al. (2019). Tumoursecreted HSP90alpha on external surface of exosomes mediates tumour stromal cell communication via autocrine and paracrine mechanisms. Sci. Rep. 9:15108. doi: 10.1038/s41598-019-51704-w

Thuringer, D., Hammann, A., Benikhlef, N., Fourmaux, E., Bouchot, A., Wettstein, G., et al. (2011). Transactivation of the epidermal growth factor receptor by heat shock protein 90 via Toll-like receptor 4 contributes to the migration of glioblastoma cells. J. Biol. Chem. 286, 3418-3428. doi: 10.1074/jbc.M110. 154823

Tian, Y., Wang, C., Chen, S., Liu, J., Fu, Y., and Luo, Y. (2019). Extracellular HSP90alpha and clusterin synergistically promote breast cancer epithelial-tomesenchymal transition and metastasis via LRP1. J. Cell Sci. 132:jcs228213. doi: $10.1242 /$ jcs. 228213

Tsen, F., Bhatia, A., O’Brien, K., Cheng, C. F., Chen, M., Hay, N., et al. (2013). Extracellular heat shock protein 90 signals through subdomain II and the NPVY motif of LRP-1 receptor to Akt1 and Akt2: a circuit essential for promoting skin cell migration in vitro and wound healing in vivo. Mol. Cell. Biol. 33, 4947-4959. doi: 10.1128/MCB.00559- 13

Tsutsumi, S., Scroggins, B., Koga, F., Lee, M. J., Trepel, J., Felts, S., et al. (2008). A small molecule cell-impermeant Hsp90 antagonist inhibits tumor cell motility and invasion. Oncogene 27, 2478-2487. doi: 10.1038/sj.onc.1210897

Ullrich, S. J., Moore, S. K., and Appella, E. (1989). Transcriptional and translational analysis of the murine $84-$ and $86-\mathrm{kDa}$ heat shock proteins. J. Biol. Chem. 264, 6810-6816.

Urabe, F., Kosaka, N., Sawa, Y., Yamamoto, Y., Ito, K., Yamamoto, T., et al. (2020). miR-26a regulates extracellular vesicle secretion from prostate cancer cells via targeting SHC4, PFDN4, and CHORDC1. Sci. Adv. 6:eaay3051. doi: 10.1126/ sciadv.aay3051
Velichko, A. K., Markova, E. N., Petrova, N. V., Razin, S. V., and Kantidze, O. L. (2013). Mechanisms of heat shock response in mammals. Cell. Mol. Life Sci. 70, 4229-4241. doi: 10.1007/s00018-013-1348-7

Wang, X., Song, X., Zhuo, W., Fu, Y., Shi, H., Liang, Y., et al. (2009). The regulatory mechanism of HSP90alpha secretion and its function in tumor malignancy. Proc. Natl. Acad. Sci. U.S.A. 106, 21288-21293. doi: 10.1073/pnas.09081 51106

Wong, D. S., and Jay, D. G. (2016). Emerging roles of extracellular Hsp90 in cancer. Adv. Cancer Res. 129, 141-163. doi: 10.1016/bs.acr.2016.01.001

Wyatt, A. R., Yerbury, J. J., Berghofer, P., Greguric, I., Katsifis, A., Dobson, C. M., et al. (2011). Clusterin facilitates in vivo clearance of extracellular misfolded proteins. Cell. Mol. Life Sci. 68, 3919-3931. doi: 10.1007/s00018-011-0684-8) 10.1007/s00018-011-0684-8

Xiao, Y., and Liu, Y. (2020). Recent advances in the discovery of novel HSP90 inhibitors: an update from 2014. Curr. Drug Targets 21, 302-317. doi: 10.2174/ 1389450120666190829162544

Zhang, G., Liu, Z., Ding, H., Zhou, Y., Doan, H. A., Sin, K. W. T., et al. (2017). Tumor induces muscle wasting in mice through releasing extracellular Hsp70 and Hsp90. Nat. Commun. 8:589. doi: 10.1038/s41467-017-00726-x

Zou, M., Bhatia, A., Dong, H., Jayaprakash, P., Guo, J., Sahu, D., et al. (2017). Evolutionarily conserved dual lysine motif determines the non-chaperone function of secreted HSP90alpha in tumour progression. Oncogene 36, 2160 2171. doi: 10.1038/onc.2016.375

Zuehlke, A. D., Beebe, K., Neckers, L., and Prince, T. (2015). Regulation and function of the human HSP90AA1 gene. Gene 570, 8-16. doi: 10.1016/j.gene. 2015.06.018

Conflict of Interest: The authors declare that the research was conducted in the absence of any commercial or financial relationships that could be construed as a potential conflict of interest.

Publisher's Note: All claims expressed in this article are solely those of the authors and do not necessarily represent those of their affiliated organizations, or those of the publisher, the editors and the reviewers. Any product that may be evaluated in this article, or claim that may be made by its manufacturer, is not guaranteed or endorsed by the publisher.

Copyright (c) 2021 Poggio, Sorge, Secli and Brancaccio. This is an open-access article distributed under the terms of the Creative Commons Attribution License (CC BY). The use, distribution or reproduction in other forums is permitted, provided the original author(s) and the copyright owner(s) are credited and that the original publication in this journal is cited, in accordance with accepted academic practice. No use, distribution or reproduction is permitted which does not comply with these terms. 